\title{
There Are No Hard-to-Serve Learners, Only Ill-Served Ones
}

\author{
Erik Jacobson, Montclair State University
}

Since it was signed into law, the Workforce Investment and Opportunity Act (WIOA) has been the subject of continuing scrutiny. One commonly shared concern is that the evaluation metrics of the Act (e.g., employment, salary, etc.) may incentivize programs to work with learners who will more readily meet expected outcomes (Pickard, 2016). Others suggest this concern is misplaced, pointing to the fact that the Act explicitly notes that the models created for State and program evaluation will be adjusted to recognize the priority given to serving students who face significant barriers (Wilson, 2015). These barriers include low levels of English and/or literacy, disabilities, limited work experience, lack of stable shelter, economic vulnerability and being an ex-offender. Learners who face these barriers are often identified as being part of hard-to-serve populations, both in policy documents and in commentary in the field. However, it is unclear what the term actually means. These populations may face difficult barriers, but why do those barriers make them harder to serve than other students? Why are certain populations singled out in this way? What purpose does it serve to attach a pejorative label to them?

Within the language of WIOA, it often seems like the definition of hard to serve is tautological in nature - that is, it is defined by the hard-to-serve populations it describes. In the WIOA Final Rule, it explains how the evaluation process is intended to account for the nature of the student population served in this way:
the model will increase the performance levels required if a State or local area were to serve lower-than-anticipated percentages of hard-to-serve populations with barriers to employment because it would presumably be easier to serve these individuals. Similarly, performance levels (or targets) would be decreased if a State or local area were to serve a higher-than-anticipated percentage of individuals with barriers, because these individuals are harder to serve. (U.S. Department of Labor and Department of Education, 2016, p. 55866)

In other words, it is more difficult to serve students with barriers that make them hard to serve. This truism does not provide any more clarity on what about those barriers make hard-toserve learners so different from other learners.

In addition to those noted above, the Act presents a number of other potential barriers that can lead to somebody being described as hard to serve, including receiving TANF or other assistance (p. 55841), taking a longer time to achieve a positive outcome (p. 55842), or being foreign born (p. 55866). Again, in none of these cases is it explained why individuals in these populations are harder to serve - it is seemingly taken for granted. The phrasing itself suggests that it is in fact an issue with the learner - something about 
them is seen as creating difficulties. However, what about a learner being foreign-born is problematic for a program providing education or training? Why would these students be harder to serve than learners born in the United States? The answer cannot be their need to improve their English skills, since that is the very purpose of English as a second language programs. Because the term is not explained or elaborated on, hard to serve is open for interpretation.

For example, one reading of the concept of hard-to-serve learners suggests that there is an issue with the learner's disposition. Consider the connotation of phrases like hard to please or hard to talk to. If a potential learner does not accept an offer to enroll in a particular program, they may be written off as not wanting help. Why might this be a population level issue rather than one of an individual's personality? Some studies (Willis, 1972) suggest that some populations might be less likely to participate in formal education if they perceive that it does not have their best interests in mind, or if it is part of a system that is tracking them into low-wage and low-status employment. However, describing learners who have doubts about formal education as hard to serve would beg the question of why they came to that conclusion. Participation and persistence must be understood as a systemic issue, rather than solely a matter of personal responsibility (Comings, 2009), so understanding hard to serve as measure of a learner's affect is problematic.

Another reading of hard-to-serve learners implies that there is an issue with the student's skill levels or understanding. The analogy here is to materials that are challenging by their nature, such as when things are described as hard to work with or hard to handle. In this case, hard to serve suggests there is a pedagogical problem created by a student demonstrating some key gaps or limitations. To use hard to serve in this way suggests a deficit model of education in which students are defined by what they are perceived to lack (Bragg, 2016). However, working with any group of learners demands on-going revision of existing curriculum and adapting instructional methods. It is true that some students may require more resources and sustained attention over a period of time but that does not make them hard to serve. All students deserve an appropriate education, so applying a pejorative label to student populations who may need more time and resources is also problematic.

Indeed, another reason why learners from certain populations might be described as hard to serve concerns the choices programs make with regards to enrollment. Despite WIOA language explaining that variations in students' backgrounds will be accounted for in evaluations, some programs remain concerned about how the skill level of the students they enroll may impact their outcomes, and thus their funding (Jacobson, 2013). In this case, describing a student population as hard to serve suggests that it is a question of economics. Given the chance that certain students might have a negative impact on evaluations and the program's bottom-line, a program may decide that it is difficult to justify making the choice to serve them. Used in this way, the term hard to serve labels some learners as potential risks, obscuring the fact that it is accountability and funding policies that create instability within programs, not the learners.

Of course, there may be other readings of hard to serve, but the three represented above are certainly problematic. What else could it mean? The term appears to be ill-defined at best, and misleading at worst. Why then is it so commonly used? Learners who are unhoused, facing food insecurity or have a disability do not present dispositional or pedagogical challenges that 
cannot be overcome, and they do not need to justify their requests for education or training. As with other labels, language that divides people into groups and categories is ideological in nature (Delpit \& Dowdy, 2002; Foucault, 1972; Volosinov, 1996). Identifying some learner populations as hard to serve is an act of othering (Said, 1978), placing them apart from, and providing definition to, those who are then conceptualized as typical learners (i.e., those that are not hard to serve).

A prominent example of the ideological nature of labels and identity is the debate around the term disabled, as discourse in the disability rights community has shifted over time (Liebowtiz, 2015). Not long ago, there was a stated preference for people-first descriptions, such as a person with a disability, because it was thought to suggest that the individual was not wholly defined by their disability. However, in recent times some people have made a strategic shift back to using the term disabled person to describe themselves. They do this in part to assert membership in a particular identity-based community (e.g., I'm Black, I'm a woman, I'm Muslim, etc.) and to call attention to the sociopolitical nature of their lived experience. Indeed, in the social model of disability (Oliver, 1990), an ontological distinction is made between an impairment and disability. For example, a person may have issues with mobility (an impairment), but it is buildings without ramps and sidewalks without curb cutouts that limits their access to the public sphere. People with certain impairments are thus disabled by a society that does not provide appropriate services. In contrast to person with a disability, the term disabled highlights the relationship between the individual and their environment (physical, social, political, economic, ideological). Rather than suggesting an inherent quality of the individual, disabled names an oppressive system that does not respect and attend to the basic rights of people with impairments (Lalvani \& Broderick, 2013).

Along these lines, the term hard-to-serve learners serves to divert attention from these same types of systemic issues within adult education. If a potential adult learner with limited mobility cannot make it to a program in the United States, the issue is not them, it is a poorly developed infrastructure that does not take their needs into account (National Disabilities Rights Network, 2019). If being unhoused makes it hard to for a potential student to be reached ("They are hard to serve because we can't find them"), the issue is not the unhoused, it is the fact that shelter is not being provided (Picture the Homeless, 2015). If being an ex-offender makes it hard for a potential learner to enroll in a training program, we need to consider the ways in which transition is hindered by policies and discourses of incarceration that perpetuate a sense of hopelessness and/or the inevitability of recidivism (Muth et. al, 2016). If receiving aid means that a learner is less likely to succeed, we need to consider whether welfare is actually designed to allow people to do more than just barely survive (Piven \& Cloward, 1993). Thus, rather than being hard to serve, it is more appropriate to describe these populations as illserved by society.

One more meaning of the term hard to serve that has been offered is that it is meant to call attention to the limited resources available for adult education and related social welfare programs. That is, it is difficult to provide services when there is no funding. That is certainly true, but why are certain student populations the ones whose rights to services are circumscribed? It is a question of economic and budgeting priorities, not the nature of the populations in question. Ending corporate tax breaks would free up more than $\$ 70$ billion 
(Gardner et al., 2019). Cuts in the U.S. military budget ( $\$ 717$ billion in 2019) could fully fund a number of essential social service programs (Koshgarian, 2019). This means we have the resources to tackle a number of seemingly intractable problems. For example, current housing policy has led to a situation in which there are scores of vacant apartments and houses for each unhoused person (Picture the Homeless, 2015). Accepting the idea that certain populations are hard to serve and will remain that way due to perceived financial constraints is a failure of political imagination. In a time when increased budget deficits in the United States have led to calls for austerity, describing certain learners as hard to serve may become a self-fulfilling prophesy - "These people are difficult to provide services to so there is only so much we can do for (or with) them." When belts are tightened, those who have been effectively othered are less likely to be taken care of.

It is worth noting that in addition to currently being ill-served, it is highly likely that these othered student populations (e.g., adults with disabilities, ex-offenders, the unhoused) have been ill-served in the past. Economic, food and shelter vulnerability have long been persistent problems in the United States, as has inequality in public school systems. For that reason, it is not appropriate to consider adult education programs a second chance - it is not clear that most adult learners were given a first chance. If somebody has been ill-served, they may in fact need more support than a student who hasn't been, but time and resource-intensive services should not be seen as some kind of excessive demand or largess. Rather, targeted and tailored services are part of a necessary restitution. If that effort is framed as being a second chance, it necessarily puts it in conflict with first chance (K-12) education and more likely to be on the budgetary chopping block.

Adult education advocates have long fought for a variety of supports that would have an immediate impact on learners and for broader structural changes. As with the disability rights movement, I think we need to stress the specific nature of the oppressions some learners face and highlight the harm being done to adult learners in vulnerable populations. I believe changing the terminology we use will limit (though not erase) the othering of learners facing certain barriers, call attention to the ways in which some adult learners are disempowered and help prioritize systemic change. It may also prove important in fights over budgets that are likely to get even more draconian with regards to social services. Recognizing that there are no hard-to-serve students, only ill-served ones, will help clarify the political project required to remove the barriers that stand in these students' way. 


\section{References}

Bragg, D. (2016). Is WIOA good for adult learners? A response to Amy Pickard's forum essay. Journal of Research and Practice for Adult Literacy, Secondary, and Basic Education, 5(2),56 - 59.

Center for Law and Social Policy (2016). WIOA performance targets: Incentives to improve workforce services for individuals with barriers to employment. https://www.clasp.org/sites/default/files/public/ resources-and-publications/publication-1/Opportunitiesfor-Action-WIOA-Performance-Targets.pdf

Comings, J. (2009). Student persistence in adult literacy and numeracy programs. In S. Reder and J. Bynner (Eds.), Tracking adult literacy and numeracy skills (pp. 160 176). Routledge.

Delpit, L., \& Dowdy, J. K. (2002). The skin that we speak: Thoughts on language and culture in the classroom. The New Press.

Foucault, M. (1972). The archeology of knowledge and the discourse on language. (R. Sawyer, Trans.). Pantheon.

Gardner, M., Roque, L. \& Wamhoff, S. (2019). Corporate tax avoidance in the first year of the Trump tax law. Institute on Taxation and Economic Policy

Jacobson, E. (2013). Investing in New Jersey's adult learners. State Council on Adult Literacy Education Services.

Koshgarian, L. (2019). The bipartisan \$738 billion military budget deal. National Priorities Project. https://www. nationalpriorities.org/blog/2019/08/09/bipartisan-738billion-military-budget-deal/

Lalvani, P. \& Broderick. A. (2013). Institutionalized ableism and the misguided "Disability Awareness Day": Transformative pedagogies for teacher education. Equity \& Excellence in Education, 46(4), 468-483.
Liebowitz, C. (2015). I am disabled: On identity-first versus people-first language. The Body Is Not an Apology. https://thebodyisnotanapology.com/magazine/i-amdisabled-on-identity-first-versus-people-first-language/

Muth, W., Warner, K., Gogia, L. \& Walker, G. (2016). A critique of the prison reentry discourse: Futurity, presence and commonsense. Prison Journal, 96, 392-414.

National Disabilities Rights Network (2019). A call to prioritize accessibility this national infrastructure week. https://www.ndrn.org/resource/national-infrastructureweek-2019

Oliver, M. (1990). The politics of disablement: $A$ sociological approach. St. Martin's Press.

Pickard, A. (2016). WIOA: Implications for low-scoring adults. Journal of Research and Practice for Adult Literacy, Secondary, and Basic Education, 5(2) 50 - 55.

Picture the Homeless (2015). Banking on vacancy: Homeless and real estate speculation. IssueLab. https://www.issuelab.org/resources/14899/14899.pdf

Piven, F. F. \& Cloward, R. (1993). Regulating the poor: The functions of public welfare. Vintage.

Said, E. (1978). Orientalism. Pantheon Books

U.S. Department of Labor and Department of Education (2016). Workforce Innovation and Opportunity Act; Joint rule for unified and combined state plans, performance accountability, and the one-stop system joint provisions; Final rule.

Volosinov, V. N. (1996). Marxism and the philosophy of language (L. Matejka \& I.R. Titunik, Trans.). Harvard University Press.

Willis, P. (1977) Learning to Labour. Saxon House.

Wilson, B. (2015). WIOA and Serving the Hard to Serve. National Skills Coalition. 